\title{
A suggested approach to patients with dyspepsia
}

\author{
ABR THOMSON MD PhD FRCPC FACG
}

\begin{abstract}
ABR ThOMSON. A suggested approach to patients with dyspepsia. Can J Gastroenterol 1997;11(2):135-140. A comprehensive review of dyspepsia is presented. Topics include causes of dyspepsia, prevalence, causes of symptoms (motility abnormalities, visceral hypersensitivity, psychosocial aspects, role of Helicobacter pylori), investigations of patients with dyspepsia and, finally, whether there is effective treatment.
\end{abstract}

Key Words: Dyspepsia, Review, Treatment

\section{Suggestion d'une approche envers les patients atteints de dyspepsie}

RÉSUMÉ : Une revue détaillée de la dyspepsie est présentée. Les sujets traités comprennent les causes de la dyspepsie, sa prévalence, les causes des symptômes (anomalies de la motilité, hypersensibilité viscérale, aspects psychologiques, rôle de Helicobacter pylori), des investigations de patients atteints de dyspepsie et, finalement, si oui ou non il existe un traitement efficace.
A comprehensive review of dyspepsia is presented. Topics discussed are causes of dyspepsia, prevalence, causes of symptoms (motility abnormalities, visceral hypersensitivity, psychosocial aspects, role of Helicobacter pylori), investigations of patients with dyspepsia and, finally, whether there is effective treatment.

\section{WHAT IS DYSPEPSIA?}

Some physicians use the term dyspepsia to refer to abdominal pain or discomfort that occurs in relation to meals or that is referable to the upper alimentary tract. An international group of clinical investigators suggested that dyspepsia be defined as the presence of episodic or persistent pain or discomfort localized to the epigastrium or upper abdomen $(1,2)$. I use the term dyspepsia to mean chronic or recurrent upper abdominal discomfort or nausea that may not be related to meals $(3,4)$. The terms nonulcer dyspepsia (NUD) and functional dyspepsia are often used interchangeably. The topic of NUD has been reviewed (5). NUD is not a single entity, but rather represents multiple syndromes. It used to be suggested that patients with dyspepsia fall into distinct symptom subgroups that may indicate different underlying etiologies (6). These groups included patients with 'classical' ulcer symptoms (termed ulcer-like dyspepsia); symptoms suggestive of gastric stasis or small bowel dysmotility (termed dysmotility-like dyspepsia); dyspepsia accompanied by symptoms suggestive of gastroesophageal reflux (termed reflux-like dyspepsia); and concurrent symptoms of irritable bowel syndrome (IBS). However, we now recognize that these dyspepsia subgroups appear to have little clinical use and may be inappropriate to classify dyspepsia (7).

Why? Because symptom groups may overlap, symptom patterns are not directly attributed to any particular pathology and symptom patterns are not necessarily diagnostic. Thus, there is a problem with subclassification by either the suggested physiological abnormalities reported by some patients (such as delayed gastric emptying or gut contractible disturbances) or by anticipated responses to therapeutic agents, which do not differentiate between patients classified into these subgroups. Nonetheless, when deciding whether 
to use a prokinetic agent or acid-lowering therapy as an initial four-week therapeutic trial in the otherwise well patient with dyspepsia, it makes sense to at least attempt to tailor the choice of medication to the patient's symptoms. Dysmotility-like dyspepsia is suggested by the symptom cluster of late postprandial fullness, bloating ('gas'), early satiety, nausea or vomiting. A prokinetic agent is a reasonable first choice. Reflux-like dyspepsia is characterized by burning retrosternal discomfort moving upwards from the epigastrum, with or without regurgitation. Indeed, when the patient presents with dominant symptoms of heartburn or regurgitation, the sensitivity of these symptoms for reflux esophagitis is $73 \%$ and $66 \%$, respectively, with specificity of $53 \%$ and $58 \%$, and positive predictive value of $70 \%(8)$. These symptoms will likely respond to a prokinetic or an antisecretory agent such as an antacid or an $\mathrm{H}_{2}$-receptor antagonist. In patients with ulcer-like dyspepsia suggested by persistent or recurrent upper abdominal pain or discomfort, particularly 'hunger pain' relieved by food or antacids or occurring at night, begin treatment with antisecretory therapy.

\section{WHAT CAUSES DYSPEPSIA?}

In patients presenting with dyspepsia, peptic ulcer disease, gastroesophageal reflux disease (GERD) and gastric cancer need to be excluded. There is considerable overlap among symptoms in patients with duodenal ulcer, gastric ulcer or NUD. For example, neither night pain (sufficient to wake the patient from sleep) nor other symptoms are useful in discriminating organic from functional gastrointestinal diseases (9). Some patients will have heartburn and acid regurgitation suggestive of GERD but have a normal upper endoscopy (hence, the term 'endoscopy-negative' dyspepsia). Although histological evidence of esophagitis may be present, sometimes absolutely no findings are found ('endoscopy-negative' GERD). Dyspepsia can also be caused by aerophagy, but it is equally common in patients with NUD, peptic ulcer disease and cholelithiasis (10).

Clinicians previously used the term ' $\mathrm{x}$-ray negative dyspepsia', now called 'endoscopy-negative dyspepsia'. Sometimes NUD is incorrectly called 'nervous dyspepsia' (the patient's symptoms are not necessarily related to their emotional state). When the ending '-itis' is used it is even less clear whether the associated gastritis or duodenitis is necessarily the cause of the dyspepsia. Symptoms alone are not sensitive in discriminating NUD from other diagnoses in patients who undergo endoscopy. For example, symptoms are useful in separating chronic peptic ulcer disease from NUD, with a sensitivity of only $55 \%$ and a specificity of $80 \%$. Symptoms are better in distinguishing GERD from NUD, with $80 \%$ sensitivity and $80 \%$ specificity. This suggests that symptoms can be used to identify patients with objective evidence of gastroesophageal reflux at endoscopy. The differential diagnosis of NUD is similar to that of GERD, with the two conditions occasionally coexisting as part of a diffuse disorder of gastrointestinal motility $(11,12)$.

Biliary pain due to cholelithiasis is different from dyspep- sia, and symptoms such as flatulence, heartburn or dyspepsia may be equally common in persons with and without gallstones. Indeed, there is no convincing evidence that gallstones cause dyspepsia in the absence of typical biliary pain (13). Of course care must be taken to ensure that dyspepsia is not associated with extraintestinal conditions such as heart failure or uremia.

IBS may be defined as persistent or recurrent abdominal pain related to defecation in the absence of demonstrable pathology (14-17). Abdominal pain is common to both IBS and NUD, and the two may coexist (15). In fact, about $80 \%$ to $90 \%$ of patients with IBS may report dyspepsia $(18,19)$. Only a minority of persons with IBS present to physicians for medical care, and the basis for this care-seeking behaviour is unclear (20). It is also unknown why many persons with these so-called functional disorders have very real symptoms yet never seek a physician's assistance (21). Anxiety that dyspeptic symptoms might signify a serious problem and stressful life events are important reasons why some persons consult a physician (22).

\section{PREVALENCE}

About $40 \%$ of referrals to gastroenterologists are for functional gastrointestinal problems (16). A study in the early 1990s in Olmsted County, Minnesota showed that the ageand sex-adjusted prevalence of dyspepsia was 25.8/100; 64\% of those questioned had ulcer-like dyspepsia, $31 \%$ had dysmotility-like dyspepsia and 38\% had reflux-like dyspepsia. There was considerable overlap among the groups (43\% of subjects with dyspepsia could be classified in more than one subgroup) and one-third of the dyspeptics also had symptoms suggestive of IBS (23).

In population studies from Europe and the United States, the reported prevalence of dyspepsia varies from $2.5 \%$ to $41 \%$ depending in part on whether patients with symptoms of GERD or IBS are included (24). Two population-based cohort studies have shown that the prevalence of dyspepsia remains approximately constant over time $(19,25)$. Dyspepsia is costly to our health care system because of the frequent need for medications and because investigations are often necessary to exclude the presence of disease.

\section{WHAT IS THE CAUSE OF SYMPTOMS?}

It remains unclear what the role of the psyche is in the pathogenesis of dyspepsia, let alone its role in intestinal motor abnormalities or $\mathrm{H}$ pylori-associated ulcer disease. While dyspepsia is a common experience, it is abnormal because there is likely an underlying disorder, not a psychological defect, producing the symptoms. The pathophysiological basis of functional bowel disorders is highly speculative, including, for example, motility disturbances, visceral hypersensitivity or psychosocial disturbances (26).

Motility abnormalities: Gastrointestinal motility is complex, with a balance of inhibitory and excitatory neuronal, humoral and mechanical factors (27). Some patients may have symptoms suggestive of a motility disorder yet do not respond to a prokinetic agent, while others will respond to a proki- 
netic without showing changes in sophisticated measures of disordered motility. From about $30 \%$ to $80 \%$ of NUD patients present with delayed gastric emptying $(28,29)$. The proportion of persons with NUD who have antral hypomotility varies from $25 \%$ to greater than $56 \%$ (29). Antral wall motion abnormalities have been reported on ultrasonography, as has been impaired accommodation of the proximal stomach to a meal (30), which may also be associated with intestinal dysmotility (31). There is a poor correlation between gastric emptying and symptoms, and these may vary independently in response to therapy (32).

Visceral hypersensitivity: Patients with NUD may have visceral hypersensitivity, with amplified conscious perception of the intestinal wall becoming apparent when gut mechanoreceptors are activated. In addition to this possible peripheral mechanism, there may be a central mechanism with aberrant processing of afferent input at spinal or brain centres (33). To illustrate a functional disorder: IBS patients are more sensitive to distension of the bowel than matched controls but are no more responsive to somatic pain, even though they may be more sensitive to visceral pain $(34,35)$. Anxiety may lower the threshold for labelling the somatic sensations caused by normal physiological events as 'painful' or 'symptoms of disease' (36).

Psyche: The psychosocial aspects of functional gastrointestinal disorders have been reviewed (37). Numerous authors have classified NUD and IBS as psychophysiological disorders in which physiological disturbances occur as an integral part of a physiological reaction $(38,39)$. An Australian study showed that anxiety and neuroticism levels may be increased in out-patients with NUD compared with asymptomatic controls, but the level was not increased when compared with that of a group of disease controls (40). A study done in the midwest United States showed that hypochondriasis weakly correlates with the presence of pain in patients with NUD, IBS and organic disease (41). However, the Minnesota Multiphasic Personality Inventory classified NUD and IBS correctly in only about one-third of those persons (41). Thus, it is questionable whether the majority of patients with functional gastrointestinal disease demonstrate major psychopathology. Indeed, while patients with NUD and IBS were more preoccupied with medical symptoms, had increased levels of depression and pessimism, were more self-centred and intended to use denial in coping with stress (as reflected by elevated Multiphasic Personality Inventory Scores on the hypochondriasis, depression and hysteria scales) compared with healthy controls, the differences were small and of minimal clinical significance.

IBS, dyspepsia and heartburn unfortunately sometimes are associated with history of self-reported sexual, physical, emotional and verbal abuse in childhood and adulthood $(16,42,43)$. It is unclear whether therapy for this abuse helps the patient's gastrointestinal complaints.

What is the role of $\mathrm{H}$ pylori? Some persons with endoscopically negative dyspepsia may have histological evidence of gastritis and associated $\mathrm{H}$ pylori infection. Is it possible that inflammation of the gastric mucosa from $\mathrm{H}$ pylori, for exam- ple, could cause symptoms of dyspepsia? H pylori gastritis may be found in about half of NUD patients, although the prevalence in asymptomatic persons in the same community may be similar $(44,45)$. Results of 16 trials of the role of $H$ pylori therapy as a cause of dyspepsia have been examined, and while eight trials reported that anti-H pylori therapy was efficacious, eight failed to detect a statistically significant benefit (46). Because of methodological problems with some of these studies, it is still not possible to conclude whether eradication of H pylori may be useful to manage NUD patients. Thus, I suspect that while there is no convincing evidence of a causal relationship between $H$ pylori and NUD (47), eventually there may be found to be a group of NUD patients whose symptoms can be improved with $H$ pylori eradication.

\section{INVESTIGATIONS}

Of course not all patients with dyspepsia require a diagnostic test; in the Canadian GERD Consensus Report (48), as well as in the Health and Public Policy Committee of the American College of Physicians (49), endoscopy for otherwise well, young dyspeptic patients is recommended only after failure of changes in lifestyle and nonresponse of symptomatic therapeutic measures such as a short course of antacids, an $\mathrm{H}_{2}$ receptor antagonist or a prokinetic agent. The average age of patients referred to endoscopy is related to the modality of referral selection from family physicians or specialists (50). Endoscopic examination of the esophagus, stomach or duodenum is the investigation of choice in patients with dyspepsia to exclude peptic ulcer disease, GERD or carcinoma.

Over the past eight to 10 years it has been suggested that the initial management of patients with dyspepsia, in the absence of 'alarm symptoms' (such as dysphagia, weight loss or anemia), should be a short empirical course of antisecretory drugs, with endoscopy advocated only for patients not responding to this trial (49). The National Institutes of Health Consensus Panel (1994) recommended that eradication therapy for an $H$ pylori infection be undertaken only when the patient has a present or past ulcer. Empirical therapy is aimed to reduce unnecessary use of health care resources by improving the symptoms of GERD and healing peptic ulcers to help the NUD patient. Recurrence or nonresponsiveness of symptoms suggests erosive esophagitis, recurrent peptic ulceration and, therefore, the possible presence of $\mathrm{H}$ pylori or gastric carcinoma. But if the therapeutic trial is aimed at healing peptic ulcers, then don't we need to know that the patient actually has an ulcer and has $H$ pylori? If $20 \%$ of patients with dyspepsia have an ulcer, over $90 \%$ of whom have an $H$ pylori infection, then should we screen every dyspeptic person for $\mathrm{H}$ pylori? If results are positive, should anti-H pylori therapy be used? We await the results of the first Canadian $\mathrm{H}$ pylori consensus guidelines for guidance on these issues.

Many of our decisions in Canadian medicine today are driven by cost considerations. What are the alternate management strategies for patients with suspected peptic ulcer disease (51)? First, decision analysis from a decision tree is 


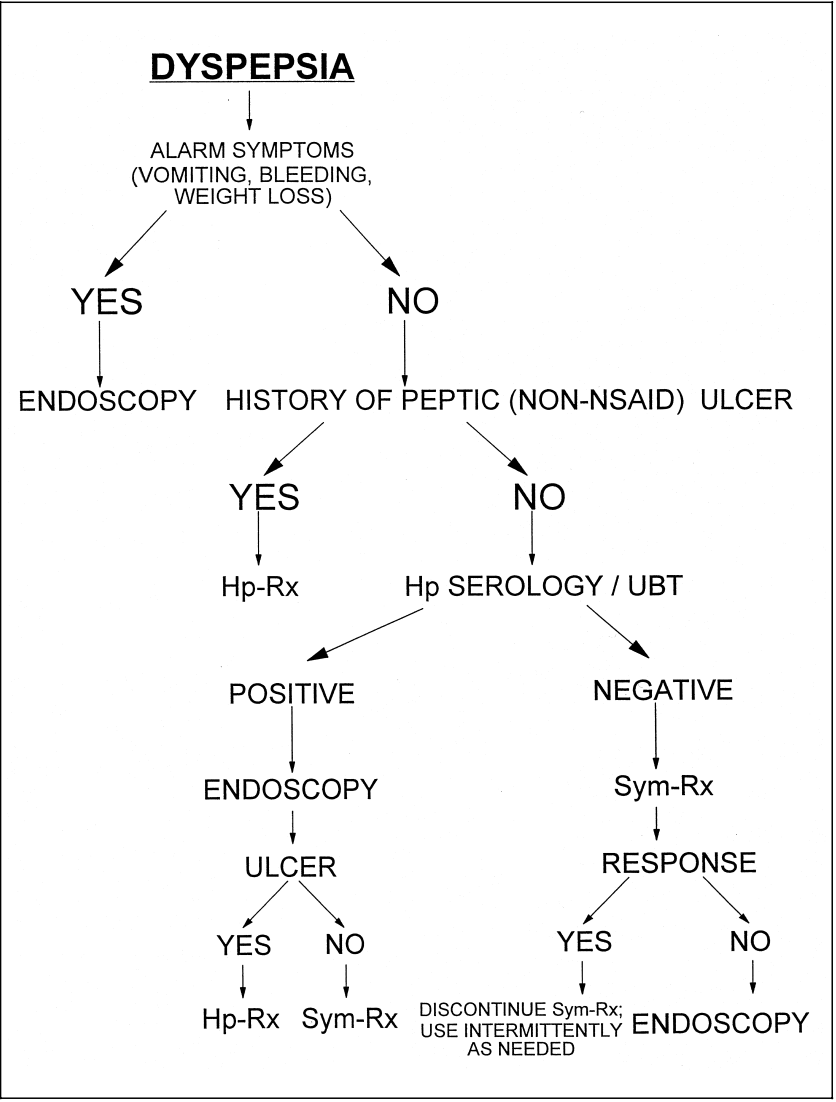

Figure 1) $\mathrm{Hp}$-Rx Eradicate Helicobacter pylori ( $\mathrm{H} p)$; Sym-Rx Treat symptoms, lifestyle changes, stop nonsteroidal anti-inflammatory drugs (NSAIDs), diet to tolerance, short course (no more than four weeks) of over-the-counter antacids $/ \mathrm{H}_{2}$-receptor antagonists, and therapeutic doses of $\mathrm{H}_{2}$-receptor antagonists, prokinetics and proton pump inhibitions. UBT Urea breath test

needed. Second, making reasonable assumptions is vital the presence of peptic ulcer disease in a dyspeptic population is $20 \%$; H pylori infection in the presence of ulcer, $95 \%$; $H$ pylori infection in the absence of ulcer, $50 \%$; ulcer healing rate after antisecretory therapy, $75 \%, \mathrm{H}$ pylori eradication rate, $80 \%$; recurrent symptom rate with active ulcer, $70 \%$; recurrent symptoms with no ulcer, $30 \%$; serious antibiotic complication rate per anti-H pylori course, $5 \%$; and sensitivity and specificity of qualitative serological test for $\mathrm{H}$ pylori, $95 \%$. Finally, sensitivity analysis to test the stability of the model is necessary. These alternate management strategies suggest that immediate endoscopic strategies are as costeffective as the empirical approaches, as long as the total endoscopy costs are less than US $\$ 500$. For most provinces, the professional, procedural and facility fees would be much less than $\mathrm{CDN} \$ 500$, let alone US $\$ 500$. But with the long waiting period to see a gastroenterologist, the empirical approach is what is actually undertaken while waiting for the diagnostic procedure!

This decision analysis was based on only $20 \%$ of dyspeptic patients having a peptic ulcer. Higher rates have been reported $(52,53)$. What is the recurrence rate of symptoms in our patient population with NUD? If greater than $70 \%$, initial endoscopy may be 'economically competitive'. We do not have 'local' Canadian data. However, when initially using the empirical treatment strategy, two-thirds of the patients eventually undergo endoscopy, with higher indirect (ie, non-third party payer) costs from sick leave days as well as ulcer drug use (54). But this again begs the question: who will do all these endoscopies? The provincial ministries will not likely support the training of a growing number of endoscopists and I doubt that there are enough of us to endoscope every dyspeptic Canadian!

I suggest that the physician take a diet history in a patient with dyspepsia, look for alterations in bowel habit and weight change, and enquire into the patient's general health to ensure that the patient does not suffer from a systemic disease (Figure 1). A four-week therapeutic trial with medication is to be undertaken, and if the patient's symptoms persist or recur, then endoscopy is indicated.

\section{IS THERE EFFECTIVE TREATMENT?}

Assuming that there are no alarm symptoms, the algorithm shown in Figure 1 may be followed. A number of factors, such as use of nonsteroidal anti-inflammatory drugs, acetaminophen, coffee, alcohol, cigarette smoking and diet (such as large meals or the ingestion of fatty foods, citrus fruits, carbonated beverages or milk in a person with lactose intolerance), may play a role in the symptoms of dyspepsia in some persons. Although lifestyle may not be a risk factor, lifestyle changes should be undertaken as part of the initial management program. While no special diet is recommended for NUD patients, they may do well if they avoid foods that trigger their symptoms or if they eat smaller meals slowly. Obvious stressors in the patient's life need to be avoided, or a coping program offered and accepted. If GERD is suspected, then appropriate lifestyle changes must be undertaken, such as weight loss, cessation of smoking, avoidance of tight-fitting clothes and elevation of the head of the bed. By the time most persons present to their physician, he or she will already have taken over-the-counter antacids, over-the-counter $\mathrm{H}_{2}$ receptor antagonists or both.

If over-the-counter measures fail and if lifestyle changes do not provide relief of the patient's symptoms, then a stepup approach may be used, comprising a short therapeutic trial with full therapeutic doses of $\mathrm{H}_{2}$-receptor antagonists, prokinetic agents or proton pump inhibitors. If the symptoms are relieved, then drug therapy is to be stopped (Figure 1). If after a successful short trial the dyspepsia returns while lifestyle changes are being maintained, the drug trial is to be repeated with the same or another class of medication. If the therapeutic trial is unsuccessful then an endoscopy is necessary. This safe approach is likely to be acceptable to most patients and provides the option of investigating only those with potentially more serious disease. The results of meta-analyses on the effectiveness of various therapeutic options in NUD are inconclusive (55-59). This is partly because of the heterogeneity of NUD and partly because the selected outcome variables may not necessarily have been validated or defined sufficiently clearly in clinical studies of NUD. Thus, 
it must be recognized that it is certain that not all patients will respond to prokinetic medications or acid-lowering therapy.

What about the future? A number of agents are currently under study for possible use in persons with NUD, such as

ACKNOWLEDGEMENTS: I thank Georgie Ingram for her word processing skills.

\section{REFERENCES}

1. Drossman DA, Thompson WG, Talley NJ, Funch-Jensen P, Janssens $\mathrm{J}$, Whitehead WE. Identification of subgroups of functional gastrointestinal disorders. Gastroenterol Intl 1990;3:159-72.

2. Drossman DA, Richter JE, Talley NJ, eds. The Functional Gastrointestinal Disorders: Diagnosis, Pathophysiology, and Treatment. New York: Little, Brown and Co, 1994.

3. Talley NJ, Phillips SF. Non-ulcer dyspepsia: potential causes and pathophysiology. Ann Intern Med 1988;108:865-79.

4. Talley NJ, Zinsmeister AR, Van Dyke C, Melton LJ. Epidemiology of colonic symptoms and the irritable bowel syndrome. Gastroenterology 1991;101:927-34.

5. Malagelada J-R. Functional dyspepsia. Insights of mechanisms and management strategies. Gastroenterol Clin North Am 1996;25:103-12

6. Colin-Jones DG. Management of dyspepsia: report of a working party. Lancet 1988;i:576-9.

7. Talley NJ. The role of Helicobacter pylori in nonulcer dyspepsia. A debate - Against. Gastroenterol Clin North Am 1993;22:153-67.

8. Klauser AE, Schindlbeck NE, Muller-Lissnor SA. Symptoms in gastro-oesophageal reflux disease. Lancet 1990;335:205-8.

9. Lawson MJ, Grant AK, Paull A, Read TR. Significance of nocturnal abdominal pain, a prospective study. BMJ 1980;2:1302.

10. Talley NJ, Piper DW. Comparison of the clinical features and illness behaviour of patients presenting with dyspepsia of unknown cause (essential dyspepsia) and organic disease. Aust NZ J Med 1986;116:352-9.

11. Cook IJ, van Eeden A, Collins SM. Patients with irritable bowel syndrome have greater pain tolerance than normal subjects. Gastroenterology 1987;93:727-33.

12. Collins SM. On the pathogenesis of the irritable bowel syndrome: The irritable bowel or the irritable patient? Can J Gastroenterol 1990;4:33-8.

13. Bainton D, Davies GT, Evans KT, Gravelle JH. Gallbladder disease. Prevalence in a South Wales industrial town. N Engl J Med 1976;294:1147-9.

14. Talley NJ, Phillips SF, Non-ulcer dyspepsia: Potential causes and pathophysiology. Ann Intern Med 1988;108:865-79.

15. Talley NJ, Piper DW. The association between non-ulcer dyspepsia and other gastrointestinal disorders. Scand J Gastroenterol 1985;20:896-900.

16. Drossman DA, Li Z, Leserman J, Toomey TC, Hu YJB. Health status by gastrointestinal diagnosis and abuse history. Gastroenterology 1996;110:999-1007.

17. Thompson WG, Dotevall G, Drossman DA, et al. Irritable bowel syndrome: guidelines for the diagnosis. Gastroenterol Int 1989;2:92-5.

18. Jones R, Lydeard S. Irritable bowel syndrome in the general population. BMJ 1992;1304:87.

19. Agreus L, Svardsudd K, Nyren O, Tibblin G. Irritable bowel syndrome and dyspepsia in the general population - overlap and lack of stability over time. Gastroenterology 1995;109:671-80.

20. Talley NJ, Colin-Jones D, Koch KL, Koch M, Nyren O, Stanghellini $V$. Functional dyspepsia: a classification with guidelines for diagnosis and management. Gastroenterol Int 1991;4:145-60.

21. Kitchen LI, Castell DO. Rationale and efficacy of conservative therapy for gastroesophageal reflux disease. Arch Intern Med 1991;151:448

22. Lydeard S, Jones R. Factors affecting the decision to consult with dyspepsia: comparison of consulters and non-consulters. J R Coll Gen Pract 1989;39:495-98.

23. Talley NJ, Zinsmeister AR, Schleck CD, Melton LJ III. Dyspepsia and dyspepsia subgroups: a population-based study. Gastroenterology 1992;102:1259-68

24. Locke GR III. The epidemiology of functional gastrointestinal
$5 \mathrm{HT}_{3}$ or $5 \mathrm{HT}_{4}$ agonists, somatostatin analogues (octroetide), gonadotropin-releasing hormone analogues (eg, leuprolide), cholecystokinin-receptor antagonists (eg, loxiglumide), calcium channel blockers and peripheral kappa receptor opiate agonists (eg, fedotozine).

disorders in North America. Gastroenterol Clin North Am 1996;25:1-19.

25. Talley NJ, Weaver AL, Zinsmeister AR, Melton JL III. Onset and disappearance of gastrointestinal symptoms and functional gastrointestinal disorders. Am J Epidemiol 1992;136:165-77.

26. Zighelboim J, Talley NJ. Viewpoints on digestive diseases. Gastroenterology 1993;104:1196-201.

27. Quigley, EMM. Gastric and small intestinal motility in health and disease. Gastroenterol Clin North Am 1996;25:113-45.

28. Klauser AG, Voderholzer WA, Knesewitsch PA, Schindlbeck NE, Müller-Lissner SA. What is behind dyspepsia? Dig Dis Sci 1993;38:147-54.

29. Malagelada J-R. Gastrointestinal motor disturbances in idiopathic dyspepsia. Scand J Gastroenterol 1991;26:29-32.

30. Gilja OH, Huasken T, Wilhelmsen I, Berstad A. Impaired accommodation of proximal stomach to a meal in functional dyspepsia. Dig Dis Sci 1996;41:689-96.

31. Malagelada J-R, Azpiroz F, Mearin F. Gastroduodenal motor function in health and disease. In: Sleisenger MIH, Fordtran JS, eds. Gastrointestinal Disease, 5th edn. Philadelphia: WB Saunders, 1993:486-508.

32. Tatsuta M, Iishi H, Nakaizumi A, Okuda S. Effect of treatment with cisapride alone or in combination with domperidone on gastric emptying and gastrointestinal symptoms in dyspeptic patients. Aliment Pharmacol Ther 1992;6:221-8.

33. Iovino P, Azpiroz F, Domingo E, Malagelada JR. The sympathetic nervous system modulates perception and reflex responses to gut distension in humans. Gastroenterology 1995;108:680-6.

34. Phillips SF, Talley NJ, Camilleri M. The irritable bowel syndrome. In: Anuras S, ed. Motility Disorders of the Gastrointestinal Tract. New York: Raven, 1992:299-326.

35. Whitehead WE, Holtkotter B, Enck P, et al. Tolerance for rectosigmoid distention in irritable bowel syndrome. Gastroenterology 1990;98:1187-92.

36. Mechanic D. Adolescent health and illness behaviour: review of the literature and a new hypothesis for the study of stress. J Hum Stress 1983;9:4-13.

37. Whitehead WE. Psychosocial aspects of functional gastrointestinal disorders. Gastroenterol Clin North Am 1996;25:21-34.

38. Hislop I. The Feeling Being. The Influence of Emotions on Illness. Perth: P Jay Publishing, 1987:87-94.

39. Dotevall G. Stress and Common Gastrointestinal Disorders. A Comprehensive Approach. New York: Praeger, 1985:39-45.

40. Talley NJ, Fung LH, Gilligan IJ, McNeil D, Piper DW. Association of anxiety, neuroticism, and depression with dyspepsia of unknown cause. A case control study. Gastroenterology 1986;90:886-92.

41. Talley NJ, Phillips SF, Bruce B, Twomey CK, Zinsmelster AR, Melton LJ III. Relation among personality and symptoms in nonulcer dyspepsia and the irritable bowel syndrome. Gastroenterology 1990;99:327-33.

42. Talley NJ, Fett SL, Zinsmeister AR, Melton LJ III. Gastrointestinal tract symptoms and self-reported abuse - a population-based study. Gastroenterology 1994;107:1040-9.

43. Talley NJ, Boyce P. Abuse and functional gastrointestinal disordersWhat is the link and should we care? Gastroenterology 1996;110:1301-4.

44. Talley NJ, Weaver AL, Tesmer DL, Zinsmelster AR. Lack of discriminant value of dyspepsia subgroups in patients referred for upper endoscopy. Gastroenterology 1993;105:1378-86.

45. Lambert JR. The role of Helicobacter pylori in nonulcer dyspepsia: A debate - For. Gastroenterol Clin North Am 1993;22:141-51.

46. Talley NJ. A critique of therapeutic trials in Helicobacter pylori-positive functional dyspepsia. Gastroenterology 1994;106:1174-83.

47. van Zanten SJ, Sherman PM. Helicbacter pylori infection as a cause of gastritis, duodenal ulcer, gastric cancer and nonulcer dyspepsia: a systematic overview. Can Med Assoc J 1994;150;177-85.

48. Beck IT, Connon J, Lemire S, Thomson ABR. Canadian Consensus Conference on the Treatment of Gastroesophageal Reflux Disease. Can J Gastroenterol 1992;6:277-89. 
49. Health and Public Policy Committee, American College of Physicians. Endoscopy in the evaluation of dyspepsia. Ann Intern Med 1985;102:266-9.

50. Mansi C, Mela GS, Pasini D, et al. Patterns of dyspepsia in patients with no clinical evidence of organic diseases. Dig Dis Sci 1990;35:1452-8.

51. Fendrick AM, Cherneu NIE, Hirth RA, Bloom BS. Alternate management strategies for patients with suspected peptic ulcer disease. Ann Intern Med 1995;123:260-8.

52. Tedesco FJ. Endoscopy in the evaluation of patients with upper gastrointestinal symptoms: indications, expectations, and interpretation. J Clin Gastroenterol 1981;3:67-71.

53. Peterson H. Over the counter sales of histamine-2 receptor antagonists. Scand J Gastroenterol 1988;155:20-2.

54. Byizer P, Hansen JM, Schaffalitzky DE, Muckadell OB. Empirical $\mathrm{H} 2$-blocker therapy or prompt endoscopy in management of dyspepsia. Lancet 1994;1343:811-6.
55. Dobfilia G, Comberlato M, Steele A, Vallaperta P. Drug treatment of functional dyspepsia. A meta-analysis of randomized controlled clinical trials. J Clin Gastroenterol 1989;111:169-77.

56. Talley NJ. Drug treatment of functional dyspepsia. Scand J Gastroenterol 1991;26:47-60.

57. Poynard T, Mory B, Levoir D, Pegnon JP, Naveau S, Chaput JC. Randomized trials in patients with dyspepsia. In: Galmiche JP, Jian R, Mognon M, Rusniewski PH, eds. Nonulcer Dyspepsia. Pathophysiology and Therapeutic Approaches. London: John Libbey and Company Ltd, 1991:227-38.

58. Rosch W. Efficacy of cisapride in the treatment of epigastric pain and concomitant symptoms in non-ulcer dyspepsia. Scand J Gastroenterol 1989;24:54-8.

59. Velduyzen van Zanter SJO, Cleary C, Talley NJ, et al. Drug treatment of functional dyspepsia: a systematic analysis of trial methodology, with recommendations for design of future trials. Am J Gastroenterol 1996;81:660-73. 


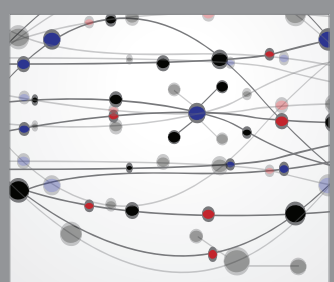

The Scientific World Journal
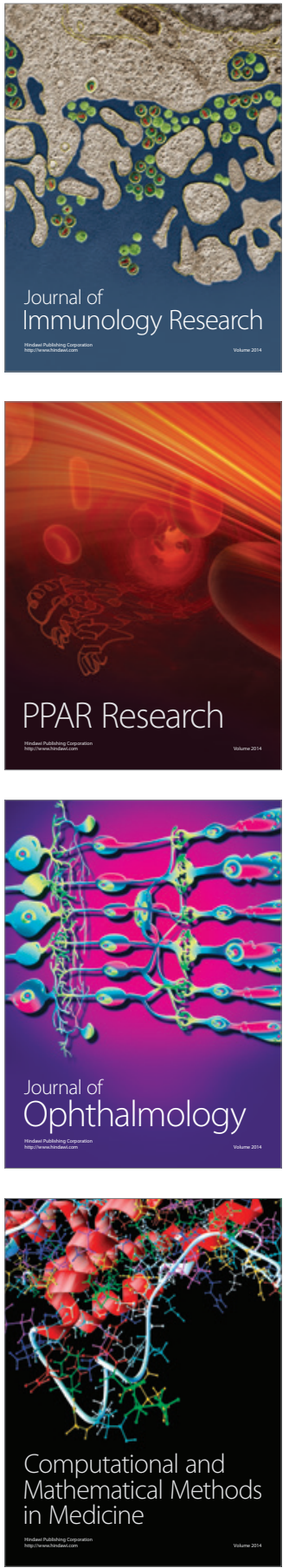

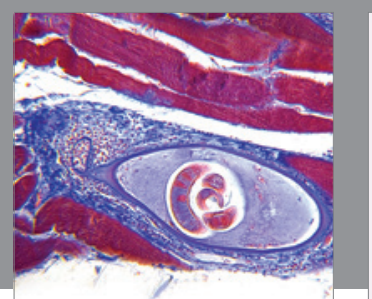

Gastroenterology Research and Practice

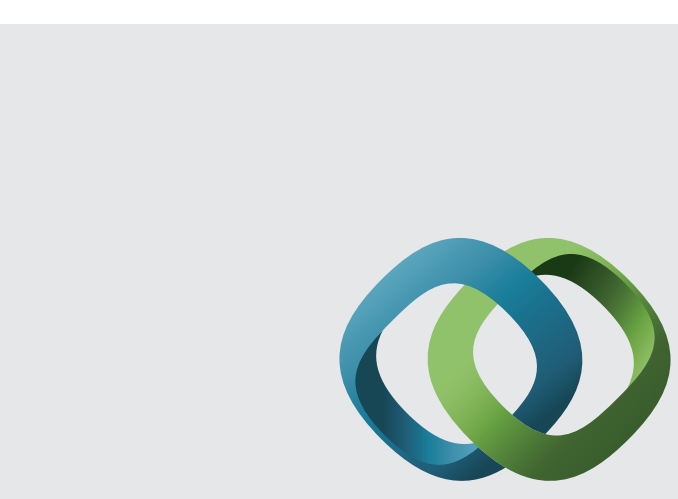

\section{Hindawi}

Submit your manuscripts at

http://www.hindawi.com
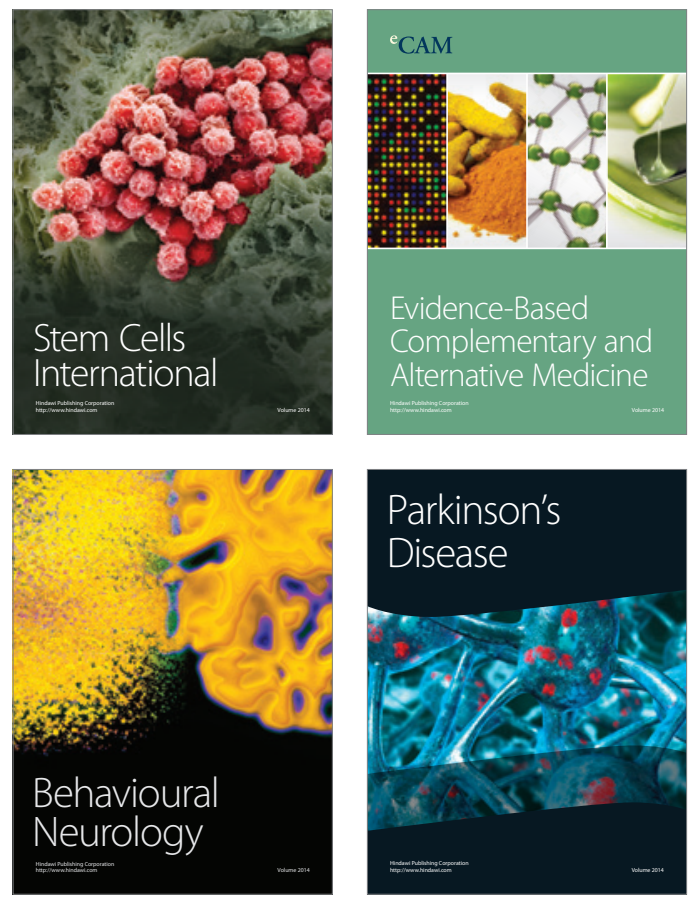
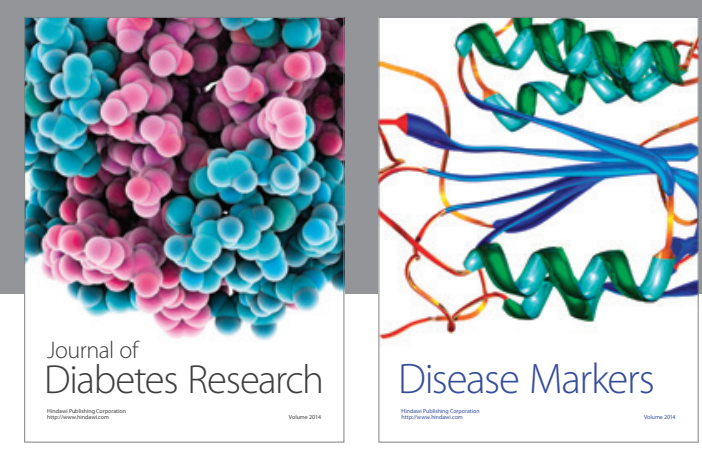

Disease Markers
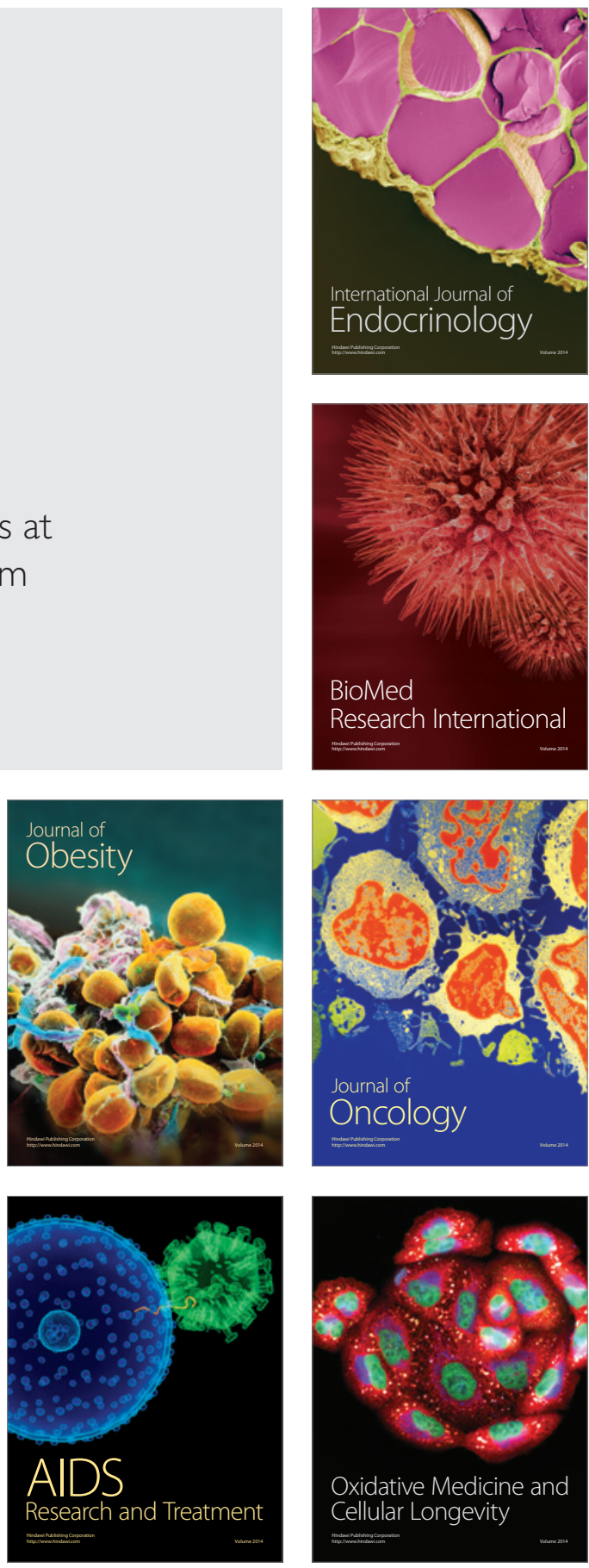